Aída Nadi Gambetta Chuk

Universidad de Puebla

\title{
VLADY KOCIANCICH Y LA IMAGINACIÓN FANTÁSTICA
}

\section{Introducción}

La obra literaria de Vlady Kociancich (Buenos Aires, 1941) entronca con la literatura fantástica argentina y, muy especialmente, con la dirección rectora de la literatura fantástica de Adolfo Bioy Casares y, de algún modo, también con la de Jorge Luis Borges, con un aire personalísimo, es decir, como un conjunto de aventuras fantásticas basadas en construcciones lógicas y en una prodigiosa imaginación fantástica que deambula, sobre todo, en metaficciones que engarzan la propia e inmediata realidad representada con las representaciones literarias de textos fantásticos de otros autores - los autores preferidos de Kociancich: Dostowiesky, Chéjov, Poe, Conrad, James, Borges, Svevo, Sciascia- sin solución de continuidad, bajo el lema de la doble identidad de vida y literatura, tanto en el caso de las representaciones propias como las ajenas, también convertidas en propias, en una suerte de espejo identitario del que pueden, consecuentemente, apropiarse los lectores. De la totalidad de las narraciones fantásticas de Kociancich ${ }^{1}$ este artículo reflexionará, principalmente, sobre La octava maravilla, Amores sicilianos y La ronda de los jinetes muertos.

\section{La octava maravilla (1982) y la casa misteriosa}

La octava maravilla, su primera novela publicada, está prologada por Adolfo Bioy Casares. ${ }^{2}$ Ofrece un universo literario que será fundante de toda su obra, con una sólida estructura narrativa y un estilo ágil y luminoso: insoslayablemente ambiguada con los temas preferenciales de las casas misteriosas y de los viajes no menos misteriosos de personajes signados por el nomadismo y que, o son artistas o tienen que ver casi siempre con lo artístico, en medio de espacios de la memoria que traslapan lo histórico y lo imaginario, amén de cierta ritualización del mal. La octava maravilla, como sus demás narraciones, parten de una óptica singularísima. El espacio fantástico no se visualiza de manera externa mundializada ni de manera local miniaturizada. Aunque Kociancich juega con el doble plano espacial, próximo a las narraciones fantásticas de Adolfo Bioy Casares, no se trata tampoco del Acá y del Allá cortazareanos. Kociancich mira el Acá (Buenos

1 Coraje (cuentos, 1971), La octava maravilla (novela, 1982), Últimos días de William Shakespeare (novela, 1984), Abisinia (novela, 1985), Todos los caminos (cuentos, 1991), Los bajos del temor (novela, 1992), El templo de las mujeres (novela, 1996), Cuando leas esta carta (cuentos, 1998), Amores sicilianos (novela, 2004), La Raza de los nerviosos (ensayo, 2006) y La ronda de los jinetes muertos (cuentos, 2007).

2 Vlady Kociancich escribía entonces Últimos días de William Shakespeare, publicada en 1984. La octava maravilla está dedicada a su esposo, Norberto de Vals, fallecido en 1997, con un epígrafe de La Tempestad (Acto 1, Escena II) de Shakespeare. Ha sido traducida al alemán como Das Drehbuch (Stuggart: Weitbrecht). En el Prólogo, Bioy Casares, recordando su propia distinción tripartita temática del género fantástico -la del terror de castillos y cadáveres, la de las utopías y la de «las construcciones lógicas, prodigiosas o imposibles, que suelen ser aventuras de la imaginación fantástica» (Kociancich, 1999: 5)- aquí ubica esta novela: «Para mí, el más extraordinario hallazgo de los últimos años ha sido La Octava maravilla de Vlady Kociancich» (Kociancich, 1999: 6). 
Aires) desde el Allá (Europa) constituyentes de un Acá portátil, o más bien, de un AcáAllá ambiguo y reversible. No hay una tranquilizadora mirada telúrica -de exaltación del color local realista, aunque el espacio propio es identificable siempre- desde la que se atisba el misterio de la ajenidad, sino el envés y el revés intercambiables e igualmente ominosos que no permiten trazar fronteras rígidas entre lo asible realista y lo extraño evanescente; antes bien, lo ficcional exhibe diferentes grados de fantasticidad. El espacio geográfico es urbano con operadores realistas como Buenos Aires y Berlín, aunque hay otras ciudades europeas como Viena, todas nimbadas por un aura de ensueños y pesadillas. El narrador-protagonista, Alberto Paradella, es un joven abogado soñador que no gusta de su profesión, se dedica a traducir y a escribir, sobre todo, el guión cinematográfico de un film premiado, «Vida y obra de Francisco Uriaga», dirigido por otro argentino que halla casualmente en Berlín, Juan Pablo Miller, nueva versión de alter ego. Paradella, que vivió siempre en la casa paterna, ya casado con Victoria, se traslada a una casa misteriosa, al sur de la ciudad. Los dobles se inician allí: un joven desquiciado que grita y en algo se le asemeja, más la figura especular de Paco Stein, su amigo de toda la vida, así como Victoria que tiene su doble en la extraña Anastasia. Cuando se divorcian, Paradella, por su trabajo, viaja a Berlín, una suerte de ciudad doble de Buenos Aires y doble ella misma, dividida aún por el Muro y, sobre todo, del barrio de Villa del Parque, ya que allí encuentra un taxista que es el doble de su padre muerto y a la dueña de la pensión, Frau Preutz, doble del recuerdo infantil de una vecina alemana, almacenera de su barrio, así como a otro doble amoroso, el de una joven de Düsseldorf, que hace lápidas. A su regreso a Buenos Aires, lo espera Alicia Martínez, otro doble erótico de la ex-esposa, en un reiterado déjà vu diegético que, para los lectores, es un déjà lu. Este neo-Ulises, que no quiere abandonar su Itaca, la recupera a través de sus viajes: la casa natal porteña, metamorfoseada maravillosamente por el recuerdo, parece ser la casa de la «sobreinfancia» propuesta por Bachelard (Bachelard, 1945: 94), en la creación artística de los poetas que invocan una lejana protección materna, quizá compartida por el protagonista y por la autora. Kociancich remite a las casas misteriosas de Poe y de James y puede inscribirse también en la literaturización de las casas siniestras de los escritores argentinos de los años 40, por la compartida dupla protección - ominosidad: Jorge Luis Borges, Adolfo Bioy Casares, Ernesto Sábato, Manuel Mujica Láinez, Beatriz Guido, Sara Gallardo, Marco Denevi ...

La octava maravilla puede leerse alegóricamente como una novela finisecular sobre la pérdida de la identidad posmoderna, pero la estructura fantástica del viaje y el uso hiperbolizado de una óptica fantástica canónicamente centrada en la duplicación espacial y de los personajes y en lo siniestro freudiano alientan una lectura decididamente fantástica en torno a la soledad casi vampírica y a la autofilia. En este mismo tenor y aún con atmósferas más ambiguas y personajes todavía más excéntricos y siempre viajeros empedernidos, son compuestas sus novelas Los bajos del temor (1992), que reúne las aventuras extravagantes contadas en Nápoles por dos letristas de una empresa discográfica, y El templo de las mujeres (1996), con una protagonista ilustradora de revistas de moda, también hiperviajera, quien en sus sempiternas huidas, se empeña en quebrar el sino fatídico de las mujeres de su familia, muertas por amores desdichados, para encontrar, paradójicamente, la salvación en Santorini, antigua Thera, una de las islas de las Cícladas, dedicada al templo de Afrodita, donde las mujeres podían ser inmortales, pero sin amor. 


\section{Amores sicilianos (2004) y la metaliteratura siciliana}

Kociancich alcanza máxima perfección estética en su última novela, Amores sicilianos, que continúa con su temática preferencial: los viajes por escenarios misteriosos -interiores y exteriores- visualizados desde una identidad femenina siempre frágil, en pos del amor esquivo, entre pasado y presente, entre Buenos Aires y Sicilia. Si La octava maravilla puede enmarcarse en un tradicional bildungsroman masculino, desde la perspectiva de un varón que persigue éxitos personales y El templo de las mujeres en un bildungsroman femenino, ${ }^{3}$ por el autodescubrimiento de la joven protagonista femenina, Amores Sicilianos en un reifungsroman ${ }^{4}$ o novela de la madurez, donde la también joven protagonista femenina construye su yo autocuestionado, emborronando los límites de la individualidad y la alteridad, de la «realidad» y la fantasía, entre su pasado propio y el pasado de otros personajes, propios de esta ficción y de otras ficciones convocadas. Amores sicilianos busca menos el respaldo de la realidad, propio de las novelas realistas, que el respaldo de la literatura; Kociancich parece evadir la «realidad» para asumir el compromiso de su novela con otras novelas. Lo inverosímil fantástico no se enfrenta a la realidad plausible, sino que constituye una inverosimilitud singular: el imaginario literario propio tiene asidero en el imaginario literario ajeno. Las vidas escritas de los personajes están atravesadas por las vidas ya leídas por la autora como lectora de su diario y de otras narraciones de autores sicilianos, así que las aventuras laberínticas de la protagonista, Julia Rossi, narradas en primera persona y que, por lo tanto, favorecen la perspectiva fantástica, suponen las relaciones entre vida y literatura, pero sobre todo entre literatura y literatura. La novela, que se abre con un título referencial y catafórico, precedido de un epígrafe de Luigi Pirandello, sobre la soledad, está estructurada con veinticuatro capítulos identificados por títulos emblemáticos. Se ofrece como la relectura de Julia, en Buenos Aires, ocho años después del regreso, de su diario de viaje por Sicilia, en septiembre de 1992, contenido en el Cuaderno Messager, cuya descripción está contenida en el primer capítulo, iluminada por la cita del verso del poeta siciliano Hippolito Pindemonte: «Cuerpos de alma vacíos». Cada capítulo posee como acápite un párrafo secuencial del diario, amén de algunos párrafos incluídos en algunos capítulos y variados autocomentarios y amplificaciones argumentales y temáticas de las peripecias del viaje siciliano, cuyo propósito expreso y no realizado es escribir un libro sobre Giuseppe Tomasi de Lampedusa, así que Amores Sicilianos afecta la forma del libro en el libro o más bien del diario en el diario, que contiene el diario releído, en una constante puesta en abismo y donde, además, el diario continente amplía el diario contenido y es su propia continuación temporal, a partir de la propuesta autoficcional. La relectura del cuaderno Messager está interceptada por una narración realista en tercera persona -capítulos 6, 7, 8, 9, 18, 19, 20, 21 22 y 23 - no sólo ajena a la voz autoconfesional de Julia, sino que parece desconocida por ella hasta la relativa asunción final -capítulo 24-, donde la protagonista vive en Buenos

\footnotetext{
${ }^{3}$ Rita Felski propone un bildungsroman femenino, en cuanto al autodescubrimiento de los sujetos femeninos (Felski, 1989: 1519).

${ }^{4}$ B. Frey Waxman cree que el reifungsroman o novela de la madurez es la que reúne narraciones íntimas, caracterizaciones, descripciones fuertemente evocativas del equipaje físico y mental soportado por los maduros y vistas interiores de su tratamiento desde los personajes más jóvenes. Todas estas narraciones difuminan los límites entre joven y viejo, realidad y fantasía, pertenencia y alteridad, integridad y fragmentación, racionalidad y senilidad (Frey Waxman, 1990: 17).
} 
Aires con Sergio Fenner, su amigo de la infancia, que escribe informes geográficos y turísticos, en sus presente y futuro de escritora. Es una suerte de contradiscurso realista del fantástico de Julia, ofrecido éste como el preferente. Ambos relatos, el fantástico de Julia y el realista de Fenner, se enuncian en torno a la temática de las casas, tanto a las casas de la realidad representada en la novela, como a las casas literarias, siniestramente misteriosas. El relato de Julia abarca las tres casas de Buenos Aires -la de Villa Urquiza, la de Montserrat y la de Luis Viale, identificadas por las calles- que heredaría de un desconocido primo siciliano, Alessandro Rossi, barón de Linosa, al regresar de Sicilia, amén de las casas sicilianas en las que se domiciliara Giuseppe Tomasi di Lampedusa. El doble espacial de Sicilia que es Buenos Aires se despliega, como aquél, en varias casas, potenciando su fantasticidad. El relato realista de Fenner, que sigue su propio monológo interior, es un interludio policial que niega la herencia siciliana y ofrece una solución verista: Andrés Cavani, ex compañero sentimental de Julia, profesor y escritor renombrado, conociendo su enfermedad terminal, aunque fallecerá por homicidio, deja en herencia a Julia las tres casas, aunque en lugar de su nombre lo reemplazará por el del supuesto primo siciliano, poniendo los trámites legales en manos del abogado Osorio, quien también escribe mediocres relatos realistas y la encomienda de convencer a Julia de aceptarlas, en manos de Fenner, al que sorpresivamente Julia ha encontrado en Sicilia. El relato de Fenner, si se lee de manera alegórica, también ironiza el sueño dorado de muchos descendientes argentinos de inmigrantes europeos que fabulaban sobre la recepción de una herencia europea, además de referirse al deseo compensatorio de los primeros inmigrantes europeos de ser multipropietarios. Julia ha aceptado la versión de la herencia siciliana e incluso ha percibido presencias extrañas, fantasmales, en la casa de Luis Viale, que Fenner niega, en su relato, por ser su vecino y no el fantasma masculino que Julia ha visto. Las casas siempre tienen mucho que decir: por ejemplo, la elegante y opresiva casa de Guise que Julia compartía con Cavani, donde es humillada por la infidelidad, la entrañable casa de la infancia de Barrancas, que nunca pudo ser propia, por pertenecer a los ferrocarriles nacionales, donde fallece Franco Rossi, el amado padre, dejándola en doloroso e incurable desamparo, por haber sido una niña abandonada por la madre y que remite a la total orfandad del padre, cuyo progenitor, Giulio Rossi, joven siciliano desembarcado en Buenos Aires, abandonó al recién nacido y a su esposa, que se ahorcó, para irse a probar fortuna en Nueva York, convencido de que «un hombre es el súbdito de sus mejores sueños» (Kociancich, 2004: 103). El tejido textual, signado por los viajes o búsquedas denodadas de egos fracturados en espacios lejanos y casas extrañas, se adensa

\footnotetext{
5 Giuseppe Maria Fabrizio Salvatore Stefano Tomasi (Palermo, 1896 - Roma, 1957), príncipe de la isla de Lampedusa, duque de Palma y Montechiaro, es conocido por su novela Il Gatopardo, que comenzó a escribir a finales de 1954, publicada en 1958, póstumamente y cuya gloria, desafortunadamente, no pudo disfrutar el autor, que en vida sufriera el rechazo editorial, en medio de su enfermedad diagnosticada como carcinoma pulmonar. Sus otras obras, todas publicadas de manera póstuma, son: I Racconti (1961), I Saggi (1977-1990), La letterature Inglese 1990-1991) y Viaggio in Europa. Epistolario1925-1930 (2006).

6 «Sé que para cada cuento o para cada novela, soy una persona diferente. Tal vez porque mis libros son autobiográficos o porque pertenezco a la clase de escritor que necesita salir de sí mismo, de sus propias circunstancias, ponerse en el lugar del otro, y escribir una novela. Naturalmente lo autobiográfico se filtra, está ahí, es inevitable. Pero la diversión está en ser otro, en otra historia, otro lugar, otro mundo. Por lo menos para mí. Entonces es un poco difícil recordar el proceso» (sobre Vlady Kociancich, 2007).
} 
más intensamente por la constante referencia al novelista siciliano Giuseppe Tomasi di Lampedusa y a la vida solitaria del autor en las casas y palazzi que habitara y a su única novela, Il Gatopardo. Lo fantástico amenaza lo cotidiano y las certidumbres tranquilizadoras de los hábitos, a la vez que manifiesta los riesgos identitarios de ser otro u otros, aunque en Kociancich ${ }^{6}$ estos riesgos de lo fantástico se convierten en los beneficios de incluir la identidad propia - de protagonista, de narradora y de autora- en otras identidades literarias coincidentes. Así, Julia se asoma a una Sicilia en decadencia en Il gatopar$d o$, novela que se inicia en 1860, en el momento histórico de la unificación de Italia, bajo el reinado del borbón Francesco II, al que visita, en Caserta, el príncipe Salina, personaje ficcional, conjuntando Historia y ficción y también autobiografía. Kociancich, en la voz de Julia retoma y hace propia la soledad de Giuseppe de Lampedusa, su amor por la literatura, su melancolía irónica por la agonizante clase aristocrática a la que perteneciera. A pesar de recorrer apasionadamente y sentirse hechizada (Kociancich, 2004:129) por las ruinas de las casas sicilianas de Giuseppe de Lapedusa -el palazzo Ganci-Volguarnera en Palermo, antiguamente Panormos, el Palazzo Filangeri-Cutó en Santa Margherita de Belice que inspirara la ficcional Donna Fugata de Il Gatopardo- y en particular por ese palazzo de Santa Margherita de Belice, descrito por el mismo autor en Los lugares de mi infancia, amén de las páginas de la biografía compuesta por David Gilmour, por haber contactado a Emiliana Borvera, experta en las casas de Lampedusa, en la «roba» siciliana (Kociancich, 2004: 143, 199), Julia no escribirá el libro ni en Sicilia ni en Buenos Aires, sintiendo el proyecto trunco como deuda culpable con Lampedusa, que no sólo amaba sino veneraba sus casas, metáforas de su ego enclaustrado y con quien ella sueña y a veces cree que ha escuchado su voz. ${ }^{7}$ Pero en un acto de magia ficcional, Kociancich exhibe, para sus lectores, en Amores sicilianos, in fieri, la extraordinaria red de textos de Julia -consignados, citados, aludidos, soñados- que no cesa de invocar la intensa memoria literaria de Lampedusa, ${ }^{8}$ «las casas de la literatura» (Kociancich, 2004: 177) y la cauda autobiográfica de las lecturas y los viajes de la autora. El perpetuum mobile de esta experimentación diegética activa, permanentemente, un diálogo entre narradora, autora y lectores, en un doble sentido: el redimensionamiento de las prácticas sociales y literarias y la desestabilización de fronteras temáticas y genéricas y de identidades propias y ajenas.

\section{La ronda de los jinetes muertos (2007) y la hipérbole onírica}

La ronda de los jinetes muertos, no azarosamente iniciado con unas líneas de Un hombre llamado Spade de Dashiell Hammet, también prioriza el tema de las casas misteriosas, protagonistas simbólicas de las narraciones de Kociancich; es un conjunto de siete relatos de impecable factura, el último de los cuales da título al libro. Están unidos por

\footnotetext{
7 « ¿Vi a Lampedusa? ¿Me habló? La falta de respuestas es lo único imaginario, lo único improbable. En términos de experiencia humana, todo lo demás es real» (Kociancich, 2004: 99).

8 Il gatopardo, novela tan leída, generadora del gatopardismo (a partir de la famosa frase de Falconeri «si vogliamo che tutto remanga come' é, bisogna che tutto cambi»), muchas veces se mezcla, en el recuerdo de los lectores, con la magnífica versión fílmica de Luchino Visconti, de 1963, que sin embargo no recogió toda la sutileza de la novela, alrededor de la inmovilidad de la sociedad siciliana, entre 1860 y 1950, sobre todo, en el momento históricopolítico que refleja, de manera sesgada, el poder de la Iglesia y también el ascenso de los grupos mafiosos.
} 
variaciones temáticas del umheimlich freudiano: sigilosos secretos de familias, de conflictos y de situaciones de indefensión y soledad y separados por ámbitos geográficos: un bazar en el Cairo, algunos barrios de la ciudad de Buenos Aires una casa en Polonia, una casa balinesa ... Los protagonistas buscan desasosegadamente sus identidades perdidas o maltratadas, en sus presentes y pasados, mezclando visiones perturbadoras, terrores hiperbolizados y sueños premonitorios, siempre al borde de la caída y siempre en procura de la salvación. La ronda de los jinetes muertos ${ }^{9}$ es un relato emblemático de la imaginación fantástica de Vlady Kociancich. Narrado en primera persona gramatical y desde la perspectiva de la víctima, a la manera de los relatos de Patricia Highsmith, reúne dos relatos: la sencilla historia de una ruptura amorosa de Paula Greene, que trabaja en una editorial y lee mucho y su marido Roger Langer y la consecuente nueva relación amorosa con un joven desconocido, Martín, nueva ruptura, denegación tanto del marido como del padre, del divorcio por intereses económicos y asesinato de Paula, a manos del amante, que será percibido por la Justicia como uno de tantos asaltos y robos violentos de algún agresor desconocido, en la ciudad de Buenos Aires y un segundo relato, que es la historia de un reiterativo sueño premonitorio de ronda mortal de los escitas, con sus caballos grises y polvorientos, que atemoriza a Paula, quien consulta a Herodoto y en sus escritos encuentra la terrible identificación de su pesadilla: los escitas constituían un muy antiguo pueblo seminómada, dedicados a la caza y a la guerra, de cultura indoeuropea que habitaron el Norte del Mar Caspio, provenientes del Asia Central, avanzaron hacia Europa en el 700 a. C. y habitaron las estepas de Ucrania; considerados pueblos salvajes por sus contemporáneos, tenían costumbres sanguinarias, sin embargo elaboraron exquisitos objetos de ornato en oro con motivos equinos, ya que no concebían la vida sin sus caballos; algunas leyendas les atribuyen rondas de la muerte a caballo en las ceremonias fúnebres, donde los reyes eran enterrados con sus principales y aún con sus caballos. Con el último aliento, Paula, atacada por el amante, reconoce la pesadilla de los escitas como un aviso desatendido por ella, en el momento de la iluminación final; cuando previa a la muerte inminente, descubre el plan del marido, que le ha enviado el supuesto enamorado y también ha planeado su asesinato por encargo. Aquí lo fantástico cuestiona otros discursos sociales: el sujeto femenino lucha contra la represión masculina en una sociedad patriarcal, donde el poder falologocéntrico opera en las realidades representadas y aún en el imaginario de las pesadillas. Si los lectores no se adhieren a la perspectiva de la protagonista, merced a esta estrategia narrativa, tienen otras soluciones, todas igualmente plausibles: otra opción realista es la del sueño premonitorio que se repite al final, no con las caras de los escitas, sino con la de sus familiares que la acosan y le niegan el divorcio y aún existe una posible lectura fantástica, la más aterradora: los escitas desestiman el tiempo y atraviesan siglos y espacios hasta realizar su ronda de la muerte en torno a Paula, lectora de Herodoto sobre los escitas, en el Buenos Aires del siglo XXI.

\footnotetext{
${ }^{9}$ Los cuentos que constituyen el libro homónimo ilustran el tema de las casas misteriosas como espacios cerrados y opresivos del inconsciente: «La puerta de Ajalil», que transcurre en El Cairo, tiene que ver con la desaparición y reaparición del hijo adoptivo de una música argentina, «El silencio de los Piquet» describe una casa de espantos, en un barrio bonaerense, habitada por unos inmigrados franceses en la segunda posguerra, «Cícladas», el relato más corto, señala un casa y una familia griegas muy extrañas, «El ojo de la iguana» cuenta la historia de un personaje femenino del pasado que reaparece en la tranquila vida de la protagonista para despojarla de sus afectos y de su casa, merced al influjo de otra casa, en Bali, «En una noche así» se mezclan, en un teatro, personajes de Shakespeare con personajes actuantes y en «Mi prima de Polonia» se asiste a la historia de Tadzio Bobrowski, un porteño descendiente de polacos, viudo, cuyo hijo lo relaciona, por internet, con Lusha, una apócrifa prima suya de Wilko, que muere suicida.
} 


\section{Conclusión}

La narrativa fantástica de Vlady Kociancich, con un estilo dinámico, crea su propio escenario discursivo y simbólico en el campo semántico de la incertidumbre, figurativizado en casas y viajes del umheimlich freudiano, protagonizados por personajes mayoritariamente femeninos y relacionados con el arte y la literatura, porque lo fantástico polemiza con otros discursos sociales para cuestionar el orden de lo llamado «real». Crea, también, las claves conjeturales estéticas e ideológicas de la recepción, en el marco del mundo cotidiano acechado por personajes y acontecimientos extraños que lo alteran y aún lo sustituyen por la otredad, asiduamente metaliteraria.

\section{BIBLIOGRAFÍA}

Arán, P. (1999): El fantástico literario. Aportes teóricos. Córdoba (Arg.): Narvaja.

Felski, R. (1989): Beyond Feminist Aesthetics. Cambridge (Mass.): Harvard University Press.

Frey Waxman, B. (1990): From de Heart to the Open Road. A Feminist Study of Aging in Contemporany Literature. Westport (Conn.): Greenwood Press.

Freud, S. (2001): «Lo siniestro». En: El hombre de la arena, precedido de Lo Siniestro, por Sigmund Freud. Palma de Mallorca: Biblioteca Nueva y Magisterio español.

Gambetta Chuk, A. N. (2000): «Poética de la casa bioycasareana». En: Literatura fantástica, Escritos, 21. Revista del Centro de Ciencias del Lenguaje (enero-junio). Puebla: Benemérita Universidad Autónoma de Puebla.

Jesenovec, M. (2001): Vlady Kociancich. Trabajo de Seminario Académico. Facultad de Filosofía y Letras, Departamento de Lenguas romances, Filología Hispánica. Buenos Aires: Universidad de Buenos Aires.

Lampedusa, G. de (2003): El Gatopardo. Madrid: Siruela.

Todorov, T. (1972): Introducción a la literatura fantástica. Buenos Aires: Tiempo Contemporáneo.

\section{La obra de Vlady Kociancich:}

La octava maravilla [1982]. Buenos Aires: Grupo Editorial Planeta, 2002.

Últimos días de William Shakespeare. Buenos Aires: Emecé, 1984.

Abisinia. Buenos Aires: Galerna/Madrid: Alfaguara, 1985.

Todos los caminos. Buenos Aires: Alfaguara, 1991.

Los bajos del temor. Barcelona: Tusquets, 1992.

El Templo de las mujeres. Barcelona: Tusquets, 1996.

Cuando leas esta carta. Buenos Aires: Seix Barral, 1998.

Amores sicilianos. Buenos Aires: Seix Barral, 2004.

La raza de los nerviosos. Buenos Aires: Seix Barral, 2006.

La ronda de los jinetes muerto. Buenos Aires: Seix Barral, 2007. 


\section{Audiovideoteca:}

http://www.buenosaires.gov.ar/areas/com_social/audiovideoteca /literatura/kociancich_tex (sobre Vlady Kociancich, 2007)

\section{Addenda:}

Premios recibidos por Vlady Kociancich:

Premio del Fondo Nacional de las Artes (1988), Premio Gonzalo Torrente Ballester (1990), Premio del Club de los Trece (1992) y Premio Kónex (1988 y 1994).

\section{VLADY KOCIANCICH IN FANTASTIČNE IZMIŠLJIJE}

Fantastična pripovedna proza Vlady Kociancich ustvarja z dinamičnim slogom lastno diskurzivno in simbolično prizorišče negotovosti, ki ga poosebljajo hiše in potovanja in kjer nastopajo večinoma ženske osebe, povezane z umetnostjo in književnostjo, kajti fantastični diskurz polemizira z drugimi družbenimi diskurzi in postavlja pod vprašaj red tako imenovanega »resničnega « sveta. Ustvarja tudi domnevna estetska in ideološka pojasnila za recepcijo v vsakdanjem svetu, kjer na nas prežijo nenavadne osebe in dogodki, ki ta svet spreminjajo ali ga nadomeščajo z drugim metaliterarnim svetom. Avtorica se v tem članku ukvarja s tremi fantastičnimi pripovedmi Vlady Kociancich, La octava maravilla, Amores sicilianos in La ronda de los jinetes muertos. 